\title{
Effects of ethanol consumption on the B-group vitamin contents of liver, blood and urine in rats
}

\author{
Aiko Miyazaki, Mitsue Sano, Tsutomu Fukuwatari and Katsumi Shibata* \\ Department of Food Science and Nutrition, School of Human Cultures, The University of Shiga Prefecture Hikone, \\ Shiga 522-8533, Japan \\ (Submitted 11 July 2011 - Final revision received 14 October 2011 - Accepted 17 October 2011 - First published online 15 December 2011)
}

\begin{abstract}
Several studies have shown that blood vitamin levels are lower in alcoholic patients than in control subjects. Acute ethanol exposure enhances the release of vitamins from liver cells in vitro. The aim of the present study is to confirm the effects of ethanol consumption on vitamin contents in vivo. We compared the contents of B-group vitamins in the liver, blood and urine between ethanol-fed and control rats fed a diet containing a sufficient- and low-vitamin mixture. The experimental rats were fed a $15 \%$ ethanol solution freely for $28 \mathrm{~d}$, and then $24 \mathrm{~h}$ urine samples were collected, after which the animals were killed. The B-group vitamin contents in the liver, blood and urine were measured. No differences in liver, blood and urine contents were observed between the control and ethanol-fed rats fed a diet containing a sufficient-vitamin mixture. On the contrary, in rats fed a diet containing a low-vitamin mixture, consumption of ethanol caused a decrease in the contents of vitamins $B_{1}, B_{2}$ and pantothenic acid in the liver; however, the contents of the other vitamins did not decrease. In the blood, the contents of vitamins $\mathrm{B}_{1}, \mathrm{~B}_{2}, \mathrm{~B}_{6}$ and pantothenic acid were lower in the ethanol-fed rats than in the controls. Urinary excretion of the B-group vitamins, except for niacin, was lower in the ethanol-fed rats. These results show that ethanol consumption affects the absorption, distribution and excretion of each of the vitamins in rats fed a diet containing a low-vitamin mixture.
\end{abstract}

\section{Key words: Vitamins: Urine: Blood: Liver: Ethanol}

Numerous studies have shown that vitamin status of alcoholic patients differs from non-drinking subjects ${ }^{(1-7)}$, and the majority have shown that blood vitamin levels are lower in alcoholic patients than in controls ${ }^{(8-10)}$. In addition, several reports have suggested that chronic alcohol feeding may lead to a significant inhibition of carrier-mediated thiamin ${ }^{(11,12)}$ and folate $^{(13-19)}$ uptake in the intestine and kidney. This phenomenon is observed only in alcoholic patients who drink ethanol chronically. On the contrary, a reduction in circulating levels of B-complex vitamins often occurred without clinical evidence of hypovitaminosis ${ }^{(20)}$. Sorrell et al. ${ }^{(21)}$ reported that the in vitro perfusion of rat liver with ethanol caused the release of all B-vitamins except biotin from the liver stores. Israel \& Smith ${ }^{(22)}$ reported that acute ethanol feeding to rats inhibited the conversion of pantothenic acid to CoA. These studies in animal models suggested that acute ethanol intake results in an increased hepatic release of vitamins and an impaired utilisation, which means increased levels of free forms of vitamins in the liver which can in turn permeate the cell membranes ${ }^{(21,22)}$. This might lead to increases in blood vitamin contents and in urinary excretion. Although there are many reports concerning the effects of ethanol on the absorption and metabolism of vitamins, the conclusion concerning the controversy remains elusive. The reason might be that there is no study regarding the simultaneous measurement of vitamin contents of liver (as a biomarker of the storage amount of vitamins), blood (as a biomarker of the circulation amount of vitamins) and urine (as a biomarker of the reabsorption ability of kidney and an extra amount of vitamins).

In the present study, we examined the effects of ethanol consumption on the contents of B-group vitamins of the liver, blood and urine in rats fed two kinds of diets containing either a sufficient- or a low-vitamin mixture.

\section{Materials and methods}

\section{Chemicals}

Vitamin-free milk casein, sucrose and L-methionine were purchased from Wako Pure Chemical Industries. Maize oil was purchased from Ajinomoto. Gelatinised maize starch, a mineral mixture (AIN-93G mineral mixture) ${ }^{(23)}$ and a vitamin mixture (nicotinic acid-free AIN-93 vitamin mixture containing

Abbreviations: 2-Py, $N^{1}$-methyl-2-pyridone-5-carboxamide; 4-Py, $N^{1}$-methyl-4-pyridone-3-carboxamide.

*Corresponding author: K. Shibata, fax +81 74928 8499, email kshibata@shc.usp.ac.jp 
$25 \%$ choline bitartrate $)^{(23)}$ were obtained from Oriental Yeast Company, Limited.

Thiamin hydrochloride $\left(\mathrm{C}_{12} \mathrm{H}_{17} \mathrm{ClN}_{4} \mathrm{OS}-\mathrm{HCl} ;\right.$ molecular weight 337.27), riboflavin $\left(\mathrm{C}_{17} \mathrm{H}_{20} \mathrm{~N}_{4} \mathrm{O}_{6} ; 376 \cdot 37\right)$, pyridoxine hydrochloride $\left(\mathrm{C}_{8} \mathrm{H}_{11} \mathrm{NO}_{3}-\mathrm{HCl} ; 205.63\right)$, cyanocobalamin $\left(\mathrm{C}_{63} \mathrm{H}_{88} \mathrm{CoN}_{14} \mathrm{O}_{14} \mathrm{P} ; \quad 1355 \cdot 40\right)$, nicotinamide $\left(\mathrm{C}_{6} \mathrm{H}_{6} \mathrm{~N}_{2} \mathrm{O}\right.$; 122.13), calcium pantothenate $\left(\mathrm{C}_{18} \mathrm{H}_{32} \mathrm{~N}_{2} \mathrm{O}_{10}-\mathrm{Ca}\right.$; 476.54), folic acid $\left(\mathrm{C}_{19} \mathrm{H}_{19} \mathrm{~N}_{7} \mathrm{O}_{6} ; 441.40\right)$ and $\mathrm{D}(+)$-biotin $\left(\mathrm{C}_{10} \mathrm{H}_{16}\right.$ $\left.\mathrm{N}_{2} \mathrm{O}_{3} \mathrm{~S} ; 244.31\right)$ were purchased from Wako Pure Chemical Industries. 4-Pyridoxic acid $\left(\mathrm{C}_{8} \mathrm{H}_{9} \mathrm{NO}_{4}=183 \cdot 16\right)$ was made by ICN Pharmaceuticals and obtained through Wako Pure Chemical Industries.

$N^{1}$-Methylnicotinamide chloride $\left(\mathrm{C}_{7} \mathrm{H}_{9} \mathrm{~N}_{2} \mathrm{O}-\mathrm{HCl} ; 159 \cdot 61\right)$ was purchased from Tokyo Kasei Kogyo. $N^{1}$-Methyl-2-pyridone-5-carboxamide (2-Py, $\mathrm{C}_{7} \mathrm{H}_{8} \mathrm{~N}_{2} \mathrm{O}_{2}$ 152-15) and $N^{1}$-methyl4-pyridone-3-carboxamide (4-Py, $\mathrm{C}_{7} \mathrm{H}_{8} \mathrm{~N}_{2} \mathrm{O}_{2}$ 152.15) were synthesised by the methods of Pullman \& Colowick ${ }^{(24)}$ and Shibata et $a{ }^{(25)}$, respectively. All other chemicals used were of highest purity available from commercial sources.

\section{Animals and treatment}

The care and treatment of the experimental animals conformed to the University of Shiga Prefecture guidelines for the ethical treatment of laboratory animals. The animals were maintained under controlled temperature $\left(22^{\circ} \mathrm{C}\right), 60 \%$ humidity and light conditions ( $12 \mathrm{~h}$ light $-12 \mathrm{~h}$ dark cycle).

Effects of ethanol feeding on the B-group vitamin contents of liver, blood and urine in rats fed a diet containing a sufficient-vitamin mixture (Expt 1)

Male Wistar rats (3 weeks old) obtained from CLEA Japan were fed freely with a conventional purified diet, consisting of $20 \%$ vitamin-free milk casein, $0 \cdot 2 \% \mathrm{~L}$-methionine, $46.9 \%$ gelatinised maize starch, $23 \cdot 4 \%$ sucrose, $5 \%$ maize oil, 3.5\% AIN-93-G mineral mixture ${ }^{(14)}$ and $1 \%$ AIN-93 vitamin mixture ${ }^{(14)}$ containing chorine bitartrate, but without nicotinic acid, to acclimatise for $7 \mathrm{~d}$. Nicotinic acid had not been added to this diet because it is supplied enough from tryptophan in casein ${ }^{(26)}$, and a dietary fibre-free diet was used because it is a tradition not to use dietary fibre in our laboratory which is not essential for normal growth ${ }^{(27)}$.

The rats were divided into two groups ( $n 5$ each). Group 1 was fed with a diet containing the $1 \%$ vitamin mixture (a sufficient-vitamin diet) and allowed to drink water for $28 \mathrm{~d}$. Group 2 was fed with a diet containing the $1 \%$ vitamin mixture (a sufficient-vitamin diet) and forced to drink a $15 \%$ ethanol solution instead of water for $28 \mathrm{~d}$. The $24 \mathrm{~h}$ urine samples were collected in amber bottles containing $1 \mathrm{ml}$ of $1 \mathrm{M}-\mathrm{HCl}$ at $09.00-09.00$ hours of the last day and were stored at $-25^{\circ} \mathrm{C}$ until required. The rats were killed at about 09.00 hours; blood was collected and tissues were taken to measure the weights and the contents of B-group vitamins in the liver, blood and urine. Liver samples were preserved at $-25^{\circ} \mathrm{C}$ until required.
Effects of ethanol feeding on the B-group vitamin contents of liver, blood and urine in rats fed a diet containing a low-vitamin mixture (Expt 2)

A preliminary experiment revealed that the body-weight gain of young rats was the same when fed a diet containing the $1 \%$ AIN-93 vitamin mixture and the $0.3 \%$ AIN-93 vitamin mixture, whereas the body-weight gain was lower in rats fed a diet containing the $0 \cdot 2 \%$ AIN-93 vitamin mixture than in those fed a diet containing the 1 or $0.3 \%$ diets. Thus, we determined tentatively whether the diet containing the $0 \cdot 3 \%$ AIN-93 vitamin mixture could supply a minimum amount of vitamins for the growing rats.

Male Wistar rats (3 weeks old) obtained from CLEA Japan were fed freely with the conventional purified diet (mentioned above) to acclimatise for $7 \mathrm{~d}$. The rats were then divided into two groups ( $n 5$ each). Group 1 was fed a diet containing the $0.3 \%$ vitamin mixture and allowed to drink water for $28 \mathrm{~d}$. Group 2 was fed a diet containing the $0.3 \%$ vitamin mixture and forced to drink a $15 \%$ ethanol solution instead of water for $28 \mathrm{~d}$. The $24 \mathrm{~h}$ urine samples and tissues were collected. Levels of alanine aminotransferase, aspartate aminotransferase and $\gamma$-glutamyltranspeptidase were measured at Mitsubishi Chemical Medience (Tokyo, Japan).

\section{Measurement of B-group vitamins in urine and blood}

Preparation and measurement of the extracts of the B-group vitamins from the urine and blood are described as follows ${ }^{(28)}$.

\section{Vitamin $B_{1}$}

Frozen liver samples, about $0.5 \mathrm{~g}$, were thawed, minced, and then added to ten volumes of 5\% ice-cold TCA and homogenised with a Digital Homogenizer Hom (Iuchi). The acidified homogenate was centrifuged at $10000 \mathrm{~g}$ for $10 \mathrm{~min}$ at $4^{\circ} \mathrm{C}$, and the supernatant was retained and used for the measurement of vitamin $\mathrm{B}_{1}{ }^{(29)}$.

\section{Vitamin $B_{2}$}

Frozen liver samples, about $0.5 \mathrm{~g}$, were thawed, minced, and then added to ten volumes of $50 \mathrm{~mm}-\mathrm{KH}_{2} \mathrm{PO}_{4}-\mathrm{K}_{2} \mathrm{HPO}_{4}$ buffer ( $\mathrm{pH}$ 7.0) and homogenised with a Teflon/glass homogeniser (Nikko Hansen). To $0 \cdot 1 \mathrm{ml}$ of the homogenate, $0.44 \mathrm{ml}$ of water and $0.26 \mathrm{ml}$ of $0.5 \mathrm{M}-\mathrm{H}_{2} \mathrm{SO}_{4}$ were added and then kept at $80^{\circ} \mathrm{C}$ for $15 \mathrm{~min}$. After cooling, $0.2 \mathrm{ml}$ of $10 \%$ TCA were added and centrifuged at $10000 \mathrm{~g}$ for $3 \mathrm{~min}$ at $4^{\circ} \mathrm{C}$. From the supernatant obtained, $0.2 \mathrm{ml}$ was withdrawn and added to $0 \cdot 2 \mathrm{ml}$ of $1 \mathrm{M}-\mathrm{NaOH}$. The alkalised mixture was irradiated with a fluorescent lamp for $30 \mathrm{~min}$ and then $0.02 \mathrm{ml}$ of glacial acetic acid were added to the mixture. The neutralised mixture was passed though a $0.45 \mu \mathrm{m}$ microfilter and the filtrate was directly injected into the HPLC system for measuring lumiflavin ${ }^{(30)}$. 


\section{Vitamin $B_{6}$}

Frozen liver samples, about $0.5 \mathrm{~g}$, were thawed, minced, and then added to $90 \mathrm{ml}$ of $55 \mathrm{~mm}-\mathrm{HCl}$ and homogenised with a Waring blender. The homogenate was autoclaved at $121^{\circ} \mathrm{C}$ for $3 \mathrm{~h}$. After cooling, the mixture was adjusted to $\mathrm{pH} 5 \cdot 0$ with $1 \mathrm{~m}-\mathrm{NaOH}$ and then made up to $100 \mathrm{ml}$ with water. The solution was filtered with qualitative filter no. 2 (ADVANTEC MFS, Inc.). The filtrate was used for measuring vitamin $\mathrm{B}_{6}$ as described previously ${ }^{(31)}$.

\section{Vitamin $B_{12}$}

Frozen liver samples, about $0.5 \mathrm{~g}$, were thawed, minced, and then added to $2.5 \mathrm{ml}$ of $0.57 \mathrm{M}$-acetic acid-sodium acetate buffer ( $\mathrm{pH} 4.5)$ plus $5 \mathrm{ml}$ of water and $0.1 \mathrm{ml}$ of $0.05 \%$ potassium cyanide (KCN). The suspension was homogenised with a Teflon/glass homogeniser. The homogenate was then put into a boiling water-bath for $5 \mathrm{~min}$. After cooling, $0.15 \mathrm{ml}$ of $10 \%$ metaphosphoric acid were added and made up to $10 \mathrm{ml}$ with water. The solution was filtered with qualitative filter no. 2 (ADVANTEC MFS, Inc.). The filtrate was used for measuring vitamin $\mathrm{B}_{12}$ as described previously ${ }^{(32)}$

\section{Nicotinamide}

Frozen liver samples, about $0.6 \mathrm{~g}$, were thawed, minced, and then added to five volumes of $0 \cdot 1 \mathrm{~g} / \mathrm{ml}$ isonicotinamide. The suspension was homogenised with a Teflon/glass homogeniser. The homogenate $(1 \mathrm{ml})$ was withdrawn and added to $4 \mathrm{ml}$ of water, and then autoclaved at $121^{\circ} \mathrm{C}$ for $10 \mathrm{~min}$. After cooling, the mixture was centrifuged at $10000 \mathrm{~g}$ for $10 \mathrm{~min}$ at $4^{\circ} \mathrm{C}$. The supernatant was retained and the precipitated materials were extracted again with $5 \mathrm{ml}$ of water, and the supernatant was retained. Both the retained supernatants were combined, and the extract was used for measuring nicotinamide as described previously ${ }^{(25)}$

\section{Pantothenic acid}

Frozen liver samples, about $0.2 \mathrm{~g}$, were thawed, minced, and then added to ten volumes of $50 \mathrm{~mm}-\mathrm{KH}_{2} \mathrm{PO}_{4}-\mathrm{K}_{2} \mathrm{HPO}_{4}$ buffer $(\mathrm{pH} 7 \cdot 0)$. The suspension was homogenised with a Teflon/glass homogeniser. The homogenate was incubated at $37^{\circ} \mathrm{C}$ overnight to convert free pantothenic acid from the bound type of pantothenate compounds. The reaction was stopped by putting it into a boiling water-bath for $5 \mathrm{~min}$. After cooling, the mixture was centrifuged at $10000 \mathrm{~g}$ for $10 \mathrm{~min}$ at $4^{\circ} \mathrm{C}$. The supernatant was retained and the precipitated materials were extracted again with $2 \mathrm{ml}$ of water, and the supernatant was retained. Both the retained supernatants were combined, and the extract was used for measuring pantothenic acid as described previously ${ }^{(33)}$.

\section{Folate}

Frozen liver samples, about $0.5 \mathrm{~g}$, were thawed, minced, and then added to ten volumes of $0 \cdot 1 \mathrm{M}-\mathrm{KH}_{2} \mathrm{PO}_{4}-\mathrm{K}_{2} \mathrm{HPO}_{4}$ buffer
(pH 6.1). The suspension was homogenised with a Teflon/ glass homogeniser. The homogenate was autoclaved at $121^{\circ} \mathrm{C}$ for $5 \mathrm{~min}$. After cooling, $2.5 \mathrm{ml}$ of pronase $(5 \mathrm{mg} / \mathrm{ml}$; Pronase MS; Kaken Pharmaceutical Company, Limited) were added and then incubated at $37^{\circ} \mathrm{C}$ for $3 \mathrm{~h}$. The reaction was stopped by putting it into a boiling water-bath for $10 \mathrm{~min}$. After cooling, $0.5 \mathrm{ml}$ of conjugase (extract from porcine kidney acetone powder, Type II; Sigma-Aldrich) were added and incubated at $37^{\circ} \mathrm{C}$ overnight. The reaction was stopped by putting it into a boiling water-bath for $10 \mathrm{~min}$. After cooling, the mixture was centrifuged at $10000 \mathrm{~g}$ for $10 \mathrm{~min}$ at $4^{\circ} \mathrm{C}$. The supernatant was retained, and the precipitated materials were extracted again with $3 \mathrm{ml}$ of water, and the supernatant was retained. Both the retained supernatants were combined, and the extract was used for measuring folate as described previously ${ }^{(34)}$. The conjugase solution was made as follows: $60 \mathrm{ml}$ of $50 \mathrm{~mm}-$ $\mathrm{KH}_{2} \mathrm{PO}_{4}-\mathrm{K}_{2} \mathrm{HPO}_{4}$ buffer ( $\mathrm{pH} 7 \cdot 0$ ) were added to $20 \mathrm{~g}$ porcine kidney acetone powder and stirred for $30 \mathrm{~min}$ at $4^{\circ} \mathrm{C}$. The suspension was centrifuged at $10000 \mathrm{~g}$ for $10 \mathrm{~min}$ at $4^{\circ} \mathrm{C}$. The supernatant was dialysed against a large amount of $50 \mathrm{~mm}-\mathrm{KH}_{2} \mathrm{PO}_{4}-$ $\mathrm{K}_{2} \mathrm{HPO}_{4}$ buffer ( $\mathrm{pH} 7 \cdot 0$ ) to remove endogenous folate of the kidney acetone powder. The dialysed conjugase solution was used.

\section{Biotin}

Frozen liver samples, about $0.5 \mathrm{~g}$, were thawed, minced, and then added to two volumes of $2 \cdot 25 \mathrm{M}-\mathrm{H}_{2} \mathrm{SO}_{4}$ and then homogenised with a Waring blender. The suspension was hydrolysed by autoclaving for $1 \mathrm{~h}$ at $121^{\circ} \mathrm{C}$. After cooling, the suspension was centrifuged at $10000 \mathrm{~g}$ for $10 \mathrm{~min}$ at $4{ }^{\circ} \mathrm{C}$, and the supernatant was used for measuring biotin ${ }^{(35)}$.

\section{Analyses}

The measurements of the B-group vitamins except for vitamin $\mathrm{B}_{6}$ were described previously ${ }^{(19)}$. The urinary excretion of 4-pyridoxic acid, a catabolite of vitamin $\mathrm{B}_{6}$, was measured according to the method of Gregory \& $\operatorname{Kirk}^{(36)}$.

\section{Statistical analysis}

Mean values between the treatment groups were compared using the Mann-Whitney $U$ two-tailed $t$ test. $P<0.05$ was considered to be statistically significant. All statistical analyses were performed using GraphPad Prism version 5.0 (GraphPad Software)

\section{Results}

Effects of ethanol feeding on the $B$-group vitamin contents of liver, blood and urine in rats fed a diet containing a sufficient-vitamin mixture (Expt 1)

There were no differences in body-weight gain and liver weights between the groups. No differences in the levels of vitamin $\mathrm{B}_{1}$, vitamin $\mathrm{B}_{2}$, vitamin $\mathrm{B}_{6}$, vitamin $\mathrm{B}_{12}$, nicotinamide, pantothenic acid, folate and biotin were observed in the liver 
and blood. Although the $24 \mathrm{~h}$ urinary excretion of some of the vitamins was slightly lower in the ethanol-treated group than in the control, the differences were not significant (data not shown). Thus, ethanol consumption did not affect the B-group vitamin contents in the liver, blood and urine when the rats were fed a diet containing sufficient amounts of the vitamins.

\section{Effects of ethanol feeding on the $B$-group vitamin contents} of liver, blood and urine in rats fed a diet containing a low-vitamin mixture (Expt 2)

As shown in Table 1, body-weight gain, food intake and liver weights were lower in the ethanol-fed group than in the controls. The overall food intake was lower in the ethanolfed group than in the controls, but energy intake was almost the same because of ethanol intake.

The effects of ethanol consumption on the activities of alanine aminotransferase, aspartate aminotransferase and $\boldsymbol{\gamma}$-glutamyltranspeptidase in plasma are shown in Table 2. No significant effects of ethanol consumption were observed for these indices of liver function.

The effects of ethanol consumption on the B-group vitamin contents of the liver are shown in Table 3. The contents of the vitamins in liver are measured as storage amounts of the vitamins, thus are expressed as mol/liver. The contents of vitamin $\mathrm{B}_{1}$, vitamin $\mathrm{B}_{2}$ and pantothenic acid were lower in the ethanol-fed group than in the controls, whereas the contents of vitamin $\mathrm{B}_{6}$, vitamin $\mathrm{B}_{12}$, nicotinamide, folate and biotin were not significantly different.

The effects of ethanol consumption on the B-group vitamin contents of the blood are shown in Table 4 . The contents of vitamin $B_{1}$, vitamin $B_{2}$, vitamin $B_{6}$ and pantothenic acid were lower in the ethanol-fed group than in the controls,

Table 1. Effects of ethanol consumption on rat body-weight gain, food intake, ethanol intake, water intake, energy intake, food efficiency ratio and liver weight (Expt 2)

(Mean values with their standard errors for five rats per group)

\begin{tabular}{|c|c|c|c|c|}
\hline & \multicolumn{2}{|c|}{ Control } & \multicolumn{2}{|c|}{$15 \%$ Ethanol } \\
\hline & Mean & SEM & Mean & SEM \\
\hline Initial body weight (g) & 36 & 1 & 36 & 1 \\
\hline Final body weight (g) & 204 & 7 & $164^{*}$ & 8 \\
\hline Body-weight gain (g/28d) & 168 & 7 & $128^{*}$ & 3 \\
\hline Food intake (g/28d) & 363 & 14 & $258^{\star}$ & 6 \\
\hline Ethanol intake $(\mathrm{g} / 28 \mathrm{~d})$ & \multicolumn{2}{|c|}{-} & 45 & 3 \\
\hline Water intake $(\mathrm{ml} / 28 \mathrm{~d})$ & 396 & 26 & \multicolumn{2}{|c|}{ - } \\
\hline Energy intake $(\mathrm{kcal} / 28 \mathrm{~d})$ & 1488 & 58 & 1396 & 56 \\
\hline Energy intake $\neq(\mathrm{kJ} / 28 \mathrm{~d})$ & 6230 & 242 & 5845 & 234 \\
\hline Food efficiency ratio§ & 0.46 & 0.01 & 0.50 & 0.00 \\
\hline Energy efficiency ratio\| & 0.113 & 0.020 & 0.092 & 0.006 \\
\hline Liver weight (g) & $9 \cdot 70$ & 0.55 & $8 \cdot 47$ & 0.36 \\
\hline
\end{tabular}

Table 2. Effects of ethanol consumption on the activities of alanine aminotransferase, aspartate aminotransferase and $\gamma$-glutamyltranspeptidase in plasma

(Mean values with their standard errors for five rats per group)

\begin{tabular}{lcccccc}
\hline & \multicolumn{2}{c}{ Control } & & \multirow{2}{*}{$15 \%$ Ethanol } \\
\cline { 2 - 3 } & Mean & SEM & & Mean & SEM \\
\hline Alanine aminotransferase (IU/I) & 22.4 & 1.9 & & 24.8 & 2.0 \\
Aspartate aminotransferase (IU/I) & 157 & 11 & & 136 & 10 \\
$\gamma$-Glutamyltranspeptidase (IU/I) & 3.2 & 0.9 & & 3.2 & 0.9 \\
\hline
\end{tabular}

whereas the contents of vitamin $\mathrm{B}_{12}$, nicotinamide, folate and biotin were not significantly different.

The effects of ethanol consumption on the $24 \mathrm{~h}$ urinary excretion of the B-group vitamins are shown in Table 5 . The excretion of vitamin $\mathrm{B}_{1}$, vitamin $\mathrm{B}_{2}$, 4-pyridoxic acid (a catabolite of vitamin $\mathrm{B}_{6}$ ), vitamin $\mathrm{B}_{12}$, pantothenic acid, folate and biotin was lower in the ethanol-fed group than in the controls, whereas the contents of nicotinamide (sum of the contents of nicotinamide and its catabolites such as $N^{1}$-methylnicotinamide, 2-Py and 4-Py) were not significantly different.

Food intake was different in the two groups, so that urinary excretion ratios of the vitamins were calculated. As shown in Table 5, the excretion ratios of all vitamins except for vitamin $\mathrm{B}_{12}$ were lower in the ethanol-fed group.

\section{Discussion}

An ordinary diet for rats generally contains sufficient amounts of nutrients including vitamins ${ }^{(23)}$. Under well-nourished conditions, rats are generally little affected by factors such as ethanol consumption. In fact, the present study proves that ethanol consumption did not affect the body-weight gain or the vitamin contents in the liver and blood when rats were fed a diet containing sufficient amounts of vitamins. On the other hand, when rats were fed a diet low in vitamins, body-weight gain was lower in the ethanol-fed group than in the control group and some vitamin contents of the liver and blood, and urinary excretion were decreased. These results show that chronic ethanol consumption affects

Table 3. Effect of ethanol consumption on liver B-group vitamin contents (Expt 2)

(Mean values with their standard errors for five rats per group)

\begin{tabular}{|c|c|c|c|c|}
\hline & \multicolumn{2}{|c|}{ Control } & \multicolumn{2}{|c|}{$15 \%$ Ethanol } \\
\hline & Mean & SEM & Mean & SEM \\
\hline Vitamin $B_{1}$ (nmol/liver) & 127 & 6 & $100^{*}$ & 4 \\
\hline Vitamin $B_{2}$ (nmol/liver) & 686 & 62 & $422^{*}$ & 16 \\
\hline Vitamin $\mathrm{B}_{6}$ (nmol/liver) & 229 & 16 & 281 & 23 \\
\hline Vitamin $\mathrm{B}_{12}$ (nmol/liver) & 0.39 & 0.03 & 0.38 & 0.02 \\
\hline Niacin ( $\mu \mathrm{mol} /$ /iver) & $18 \cdot 2$ & 1.8 & $16 \cdot 6$ & 1.3 \\
\hline Pantothenic acid ( $\mu \mathrm{mol} / \mathrm{liver})$ & $3 \cdot 16$ & 0.19 & $2 \cdot 42^{*}$ & 0.18 \\
\hline Folate (nmol/liver) & $70 \cdot 0$ & $9 \cdot 7$ & $73 \cdot 6$ & $9 \cdot 3$ \\
\hline Biotin (nmol/liver) & $9 \cdot 31$ & $1 \cdot 10$ & $9 \cdot 65$ & 0.46 \\
\hline
\end{tabular}

* Mean values were significantly different from those of the control group $(P<0.05$; Mann-Whitney $U$ two-tailed $t$ test). 
Table 4. Effect of ethanol consumption on blood B-group vitamin contents (Expt 2)

(Mean values with their standard errors for five rats per group)

\begin{tabular}{lccccc}
\hline & \multicolumn{2}{c}{ Control } & & \multirow{2}{*}{$15 \%$ Ethanol } \\
\cline { 2 - 3 } & Mean & SEM & & Mean & SEM \\
\hline Vitamin $\mathrm{B}_{1}(\mathrm{pmol} / \mathrm{ml})$ & 159 & 4 & & $139^{*}$ & 6 \\
Vitamin $\mathrm{B}_{2}(\mathrm{pmol} / \mathrm{ml})$ & 177 & 5 & & $142^{*}$ & 4 \\
Vitamin $\mathrm{B}_{6}(\mathrm{nmol} / \mathrm{ml})$ & 0.49 & 0.04 & & $0.34^{*}$ & 0.02 \\
Vitamin $\mathrm{B}_{12}(\mathrm{pmol} / \mathrm{ml})$ & 1.55 & 0.03 & & 1.41 & 0.01 \\
Niacin $(\mathrm{nmol} / \mathrm{ml})$ & 127 & 6 & & 117 & 2 \\
Pantothenic acid $(\mathrm{nmol} / \mathrm{ml})$ & 1.13 & 0.04 & & $0.89^{*}$ & 0.04 \\
Folate $(\mathrm{pmol} / \mathrm{ml})$ & 149 & 4 & & 138 & 10 \\
Biotin $(\mathrm{pmol} / \mathrm{ml})$ & 30.4 & 3.4 & & 25.9 & 1.0 \\
\hline
\end{tabular}

* Mean values were significantly different from those of the control group $(P<0.05$; Mann-Whitney $U$ two-tailed $t$ test).

absorption, distribution and excretion of vitamins, as reported previously ${ }^{(1-19)}$. The present findings are not consistent with the in vitro perfusion of rat liver with ethanol, which caused the release of all B-vitamins except biotin from the liver stores $^{(23)}$. This phenomenon was not observed in the present whole-body experiment, because the vitamin contents of the blood were not increased by ethanol consumption. In the present in vivo experiment, any vitamins released from the liver were quickly absorbed by non-hepatic tissues. In humans, the typical dietary vitamin intakes are generally around the minimum requirements. Thus, the nutritional status of rats fed a diet low in vitamins was similar to that of humans. Ethanol consumption was $45 \mathrm{~g}$ over $28 \mathrm{~d}$, so that daily average ethanol consumption was about $1.6 \mathrm{~g} / \mathrm{d}$, which corresponds to an energy intake of $46.9 \mathrm{~kJ}(11.2 \mathrm{kcal}) / \mathrm{d}$. The energy intake in the ethanol-fed group, including ethanol energy, was $5845 \mathrm{~kJ}(1396 \mathrm{kcal})$ over $28 \mathrm{~d}$ (about $209 \mathrm{~kJ}(50 \mathrm{kcal}) / \mathrm{d})$. Thus, ethanol accounted for $20 \%$ of dietary energy. Under these conditions, liver functions in rats were not injured. If humans were to consume $10467 \mathrm{~kJ}(2500 \mathrm{kcal}) / \mathrm{d}$, the equivalent ethanol consumption would be about $70 \mathrm{~g} / \mathrm{d}$, which corresponds to 1 litre of typical beer.

Vitamin depletion, common in malnourished alcoholic patients $^{(10)}$, can occur despite vitamin supplementation. Vitamin malabsorption ${ }^{(37)}$, exacerbated by malnutrition, contributes to this depletion ${ }^{(38)}$. Also, in alcoholic patients, the impaired ability of the liver to bind and store vitamins might contribute to this depletion. This may probably be due to the hepatotoxicity of ethanol, which impairs not only the vitamin-binding capacity but also the vitamin storage of the liver. In the present study, a diet containing $20 \%$ casein supplemented with methionine was used, which is an excellent protein source from a nutritional standpoint. This suggest the reasons why ethanol consumption did not cause any severe damage, such as an extremely low food intake and body-weight gain and roughness of fur for the rats, even when they were fed a low-vitamin diet.

Sorrell et al. ${ }^{(21)}$ reported that the in vitro perfusion of rat liver with ethanol caused the release of all vitamins from the liver stores, especially thiamin. It is generally considered that this phenomenon causes increased urinary excretion of vitamins, but in the present in vivo experiments, ethanol consumption did not cause increased urinary excretion, but rather decreased it. This discrepancy between the expected and the actual findings may be attributed to the difference between the in vitro and in vivo experiments. Moreover, there are differences in short-term and long-term adjustment mechanisms for ethanol toxicity. The protein nutritional status was high in the present study because the diet used $20 \%$ casein supplemented with methionine. Protein plays a pivotal role in vitamin absorption and storage in hepatocytes. Protein malnutrition causes malabsorption, reduced storage and impaired utilisation of vitamins. Thus, an adequate intake of vitamins, and also protein, is essential for preventing ethanol toxicity.

In the present study on the low-vitamin diet, vitamin $\mathrm{B}_{1}$, vitamin $B_{2}$ and pantothenic acid contents in the liver and blood were lower in the ethanol-fed group than in the controls, even when rats were fed a high-protein diet. Furthermore, the total urinary excretion and excretion ratios of all three vitamins were also lower in the ethanol-fed group. Thus, ethanol consumption reduced the intestinal absorption of these vitamins, as reported by Subramanya et $a l^{(12)}$, Hamid et al. ${ }^{(13,14,16,17)}$ and Wani \& Kaur ${ }^{(19)}$. Vitamins such as

Table 5. Effect of ethanol consumption on urinary B-group vitamin excretion (upper row) and urinary excretion ratio (lower row) for each of the vitamins (Expt 2) $\dagger$

(Mean values with their standard errors for five rats per group)

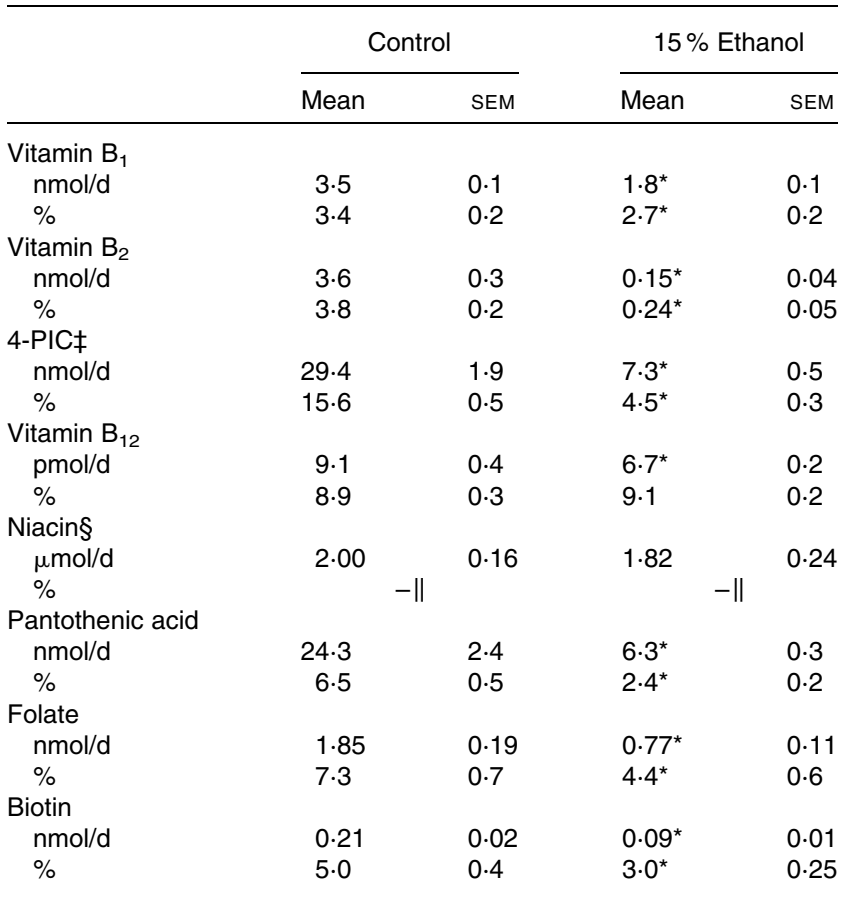

4-PIC, 4-pyridoxic acid.

* Mean values were significantly different from those of the control group $(P<0.05$; Mann-Whitney $U$ two-tailed $t$ test)

†Percentage urinary excretion ratio was calculated using the following equation: $(24 \mathrm{~h}$ urinary excretion $(\mathrm{mol} / \mathrm{d}) /$ intake of the vitamin during urine collection $(\mathrm{mol} / \mathrm{d})) \times 100$.

$\ddagger$ A catabolite of vitamin $B_{6}$.

$\S$ Niacin content was calculated as the sum of the nicotinamide content and its catabolites such as $N^{1}$-methylnicotinamide, $N^{1}$-methyl-2-pyridone-5-carboxamide and $N^{1}$-methyl-4-pyridone-3-carboxamide.

|| Urinary excretion ratio was not calculated as niacin was derived from tryptophan. 
vitamin $\mathrm{B}_{1}$, vitamin $\mathrm{B}_{2}$ and pantothenic acid might be directly and/or indirectly involved in the metabolism of ethanol, indicating that the vitamin catabolites increased and were excreted into the urine. Of these three vitamins, only the catabolic fate of vitamin $B_{1}$ is relatively well known. It has been reported that the excretion of vitamin $B_{1}$ metabolites usually exceeds by far the excretion of intact vitamin $B_{1}$ using radioactive tracer experiments ${ }^{(39)}$. The major metabolites of vitamin $B_{1}$ in rat urine are 2-methyl-4-amino-5-pyridinecarboxylic $\operatorname{acid}^{(40)}$, 4-methylthiazole-5-acetic $\operatorname{acid}^{(41)}$ and thiamine acetic acid ${ }^{(42)}$. Pearson ${ }^{(39)}$ reported that the sum of the metabolites accounted for about $50 \%$ of the total urinary excretion of vitamin $B_{1}$ and its catabolites from radioactive tracer experiments. Although we cannot measure the catabolites of vitamin $\mathrm{B}_{1}$, these metabolites might increase in the urine of the ethanol-fed rats. It is likely that a similar phenomenon would apply for the fates of vitamin $\mathrm{B}_{2}$ and pantothenic acid.

The content of vitamin $\mathrm{B}_{6}$ in the blood was lower in the ethanol-fed group, but the content of vitamin $\mathrm{B}_{6}$ in the liver was slightly higher in the ethanol-fed group than in the control. The urinary excretion of vitamin $\mathrm{B}_{6}$, determined from its catabolite 4-pyridoxic acid, was much lower in the ethanol-fed group than in the control. Probably ethanol consumption resulted in an increased storage of vitamin $\mathrm{B}_{6}$ in the liver.

Other B-group vitamin contents in the liver and blood, such as vitamin $\mathrm{B}_{12}$, nicotinamide, folate and biotin, were not affected by ethanol consumption. The lack of any effect of ethanol consumption on the niacin content in this experiment was probably because nicotinamide was synthesised from tryptophan, which was present in the diet as casein and was supplied adequately ${ }^{(43)}$. For rats, NAD precursors such as nicotinic acid and nicotinamide are not essential. In fact, the urinary excretion of nicotinamide did not differ between the two groups. Concerning the effect of ethanol consumption on biotin, Sorrell et al. ${ }^{(21)}$ reported that the in vitro perfusion of rat liver with ethanol did not cause the release of biotin, but caused the release of vitamin $B_{12}$ first. In the present experiment, a similar phenomenon was observed for biotin, but not for vitamin $\mathrm{B}_{12}$. Frank et al. ${ }^{(44)}$ reported that the first vitamin released into the circulation during hepatic insult by ethanol is vitamin $B_{12}$. This disparity between the reported and the present findings might also arise from the difference in protein nutritional status.

There are many reports concerning how ethanol consumption affects folate absorption and metabolism ${ }^{(13-18,45-53)}$. Some studies have reported that ethanol consumption increased the urinary excretion of folates ${ }^{(46,47,50-53)}$ and caused decreased serum folate levels. Romanoff et al. ${ }^{(53)}$ reported that acute ethanol exposure inhibits the apical transport of 5-methyltetrahydrofolate in cultured human proximal tubule cells, and in subchronic ethanol studies, increasing concentrations of ethanol resulted in an up-regulation of folate transporters. Furthermore, Romanoff et al. ${ }^{(53)}$ reported that both the folate receptor and reduced folate carrier transporter proteins were up-regulated in rats receiving an ethanol diet. On the contrary, Hamid et al. ${ }^{(13,14,16,17)}$ and Wani \& Kaur $^{(19)}$ reported that ethanol reduced the intestinal uptake of folate by altering the binding and transport kinetics of the folate transport system and also the expression of folate transporters in the intestine. In addition, Hamid \& Kaur ${ }^{(15)}$ reported that ethanol consumption reduces folate re-uptake in the renal absorption system by the decreased expression of transporters. The present data for folate are not consistent with previous reports ${ }^{(13-18,45-53)}$; the contents of folate in the liver and blood were not affected by ethanol consumption, and the urinary excretion of folate and the excretion ratio were decreased markedly. A study ${ }^{(52)}$ reported that urinary folate excretion increased in ethanol-fed rats consuming folate-containing diets, but not in rats fed folate-deficient diets. In the present study, the urinary excretion of folate did not increase, but decreased. This was because the diet was low in folate. In the present study, the urinary excretion of folate was lower in the ethanol-fed group than in the non-ethanol group, suggesting that ethanol consumption and the feeding of a low-folate diet up-regulated the folate receptor and reduced folate carrier transporter proteins. This up-regulation was probably a compensatory response to counteract the effects of ethanol in inhibiting the reabsorption of folate. Therefore, the effects of ethanol would depend on the dose and duration of treatment.

In summary, these results show that ethanol consumption affects the absorption, distribution and excretion of each of the vitamins in rats fed a diet containing a low-vitamin mixture. On the other hand, when rats were fed a $20 \%$ casein diet containing a sufficient amount of vitamins, ethanol consumption did not affect any factors that we measured.

\section{Acknowledgements}

This study was part of the project 'Studies on the Dietary Reference Intakes for Japanese' (principal investigator, K. S.), which was supported by a Research Grant for Comprehensive Research on Cardiovascular and Life-Style Related Diseases from the Ministry of Health, Labour and Welfare of Japan. The authors' responsibilities are as follows: A. M. designed the study, performed the experiments and prepared the manuscript; M. S. and T. F. helped in the study design, performed the experiments and assisted with the data analysis; K. S. contributed to the study design and supervised the study. The authors declare that they have no conflict of interest.

\section{References}

1. Bonjour JP (1979) Vitamins and alcoholism. I. Ascorbic acid. Int J Vitam Nutr Res 49, 434-441.

2. Bonjour JP (1980) Vitamins and alcoholism. II. Folate and vitamin $\mathrm{B}_{12}$. Int J Vitam Nutr Res 50, 96-121.

3. Bonjour JP (1980) Vitamins and alcoholism. III. Vitamin $B_{6}$. Int J Vitam Nutr Res 50, 215-230.

4. Bonjour JP (1980) Vitamins and alcoholism. IV. Thiamin. Int J Vitam Nutr Res 50, 321-338.

5. Bonjour JP (1980) Vitamins and alcoholism. V. Riboflavin. VI. Niacin. VII. Pantothenic acid. VIII. Biotin. Int J Vitam Nutr Res 50, 425-440.

6. Bonjour JP (1981) Vitamins and alcoholism. IX. Vitamin A. Int J Vitam Nutr Res 51, 166-177. 
7. Bonjour JP (1981) Vitamins and alcoholism. X. Vitamin D, XI. Vitamin E, XII. Vitamin K. Int J Vitam Nutr Res 51, 307-318.

8. Leevy CM, Baker H, TenHove W, et al. (1965) B-Complex vitamins in liver disease of the alcoholic. Am J Clin Nutr 16, 339-346.

9. Leevy CM, Thompson A \& Baker H (1970) Vitamins and liver injury. Am J Clin Nutr 23, 493-499.

10. Baker H, Frank O, Ziffer H, et al. (1964) Effect of hepatic disease on liver B-complex vitamin titers. Am J Clin Nutr 14, 1-6.

11. Subramanian VS, Subramanya SB, Tsukamoto H, et al. (2010) Effect of chronic alcohol feeding on physiological and molecular parameters of renal thiamin transport. $A m \mathrm{~J}$ Physiol Renal Physiol 299, F28-F34.

12. Subramanya SB, Subramanian VS \& Sain HM (2010) Chronic alcohol consumption and intestinal thiamin absorption: effects on physiological and molecular parameters of the uptake process. Am J Physiol Gastrointest Liver Physiol 299, G23-G31.

13. Hamid A \& Kaur J (2007) Long-term alcohol ingestion alters the folate-binding kinetics in intestinal brush border membrane in experimental alcoholism. Alcohol 41, 441-446.

14. Hamid A, Kaur J \& Mahmood A (2007) Evaluation of the kinetic properties of the folate transport system in intestinal absorptive epithelium during experimental ethanol ingestion. Mol Cell Biochem 304, 265-271.

15. Hamid A \& Kaur J (2007) Decreased expression of transporters reduces folate uptake across renal absorptive surfaces in experimental alcoholism. J Membr Biol 220, 69-77.

16. Hamid A, Wani NA, Rana S, et al. (2007) Down-regulation of reduced folate carrier may result in folate malabsorption across intestinal brush border membrane during experimental alcoholism. FEBS J 274, 6317-6328.

17. Hamid A, Kiran M, Rana S, et al. (2009) Low folate transport across intestinal basolateral surface is associated with down-regulation of reduced folate carrier in in vivo model of folate malabsorption. IUBMB Life 61, 236-243.

18. Hamid A \& Kaur J (2009) Role of signaling pathways in the regulation of folate transport in ethanol-fed rats. $J$ Nutr Biochem 20, 291-297.

19. Wani NA \& Kaur J (2010) Reduced levels of folate transporters (PCFT and RFC) in membrane lipid rafts result in colonic folate malabsorption in chronic alcoholism. $J$ Cell Physiol 226, 579-587.

20. Leevy CM, George WS, Ziffer H, et al. (1960) Pantothenic acid, fatty liver and alcoholism. J Clin Invest 39, 1005.

21. Sorrell MF, Baker H, Barak AJ, et al. (1974) Release by ethanol of vitamins into rat liver perfusates. Am J Clin Nutr 27, $743-745$.

22. Israel BC \& Smith CM (1987) Effects of acute and chronic ethanol ingestion on pantothenate and CoA status of rats. J Nutr 117, 443-451.

23. Reeves PG (1997) Components of the AIN-93 diets as improvements in the AIN-76A diet. J Nutr 127, 838S-841S

24. Pullman ME \& Colowick SP (1954) Preparation of 2- and 6-pyridones of $N^{1}$-methylnicotinamide. J Biol Chem 206 121-127.

25. Shibata K, Kawada T \& Iwai K (1988) Simultaneous microdetermination of nicotinamide and its major metabolites, $N^{1}$-methyl-2-pyridone-5-carboxamide and $N^{1}$-methyl-3-pyridone-4-carboxamide, by high-performance liquid chromatography. J Chromatogr 424, 23-28

26. Shibata K, Mushiage M, Kondo T, et al. (1995) Effects of vitamin $\mathrm{B}_{6}$ deficiency on the conversion ratio of tryptophan to niacin. Biosci Biotechnol Biochem 59, 2060-2063.
27. Fukuwatari T, Wada H \& Shibata K (2008) Age-related alterations of B-group vitamin contents in urine, blood and liver from rats. J Nutr Sci Vitaminol 54, 357-362.

28. Shibata K, Fukuwatari T, Ohta M, et al. (2005) Values of water-soluble vitamins in blood and urine of Japanese young men and women consuming a semi-purified diet based on the Japanese Dietary Reference Intakes. J Nutr Sci Vitaminol 51, 319-328.

29. Fukuwatari T, Suzuura C, Sasaki R, et al. (2004) Action site of bisphenol A as metabolic disruptor lies in the tryptophannicotinamide conversion pathway. J Food Hyg Soc Jpn 45, 231-238.

30. Ohkawa H, Ohishi N \& Yagi K (1982) A simple method for micro-determination of flavin in human serum and whole blood by high-performance liquid chromatography. Biochem Int 4, 187-194.

31. AOAC International (1995) Official Methods of Analysis, 16th ed. Arlington, VA: AOAC International.

32. Watanabe F, Abe K, Katsura H, et al. (1998) Biological activity of hydroxo-vitamin $\mathrm{B}_{12}$ degradation product formed during microwave heating. J Agric Food Chem 46, $5177-5180$

33. Skeggs H \& Wright LD (1944) The use of Lactobacillus arabinosus in the microbiological determination of pantothenic acid. J Biol Chem 156, 21-26.

34. Aiso K \& Tamura T (1998) Trienzyme treatment for food folate analysis. Optimal $\mathrm{pH}$ and incubation time for $\alpha$-amylase and protease treatment. J Nutr Sci Vitaminol 44, 361-370.

35. Fukui T, Inuma K, Oizumi J, et al. (1994) Agar plate method using Lactobacillus plantarum for biotin determination in serum and urine. J Nutr Sci Vitaminol 40, 491-498.

36. Gregory JF 3rd \& Kirk JR (1979) Determination of urinary 4-pyridoxic acid using high performance liquid chromatography. Am J Clin Nutr 32, 879-883.

37. Thomson AD, Baker H \& Leevy CM (1970) Patterns of ${ }^{35} \mathrm{~S}$-thiamine hydrochloride absorption in the malnourished alcoholic patients. J Lab Clin Med 76, 34-45.

38. Leevy CM \& Baker H (1968) Vitamins and alcoholism. Am J Clin Nutr 21, 1325-1328.

39. Pearson WN (1967) Blood and urinary vitamin levels as a potential indices of body stores. Am J Clin Nutr 20, 514-525.

40. Neal RA \& Pearson WN (1964) Studies of thiamine metabolism in the rat. II. Isolation and identification of 2-methyl-4-amino-5-pyridinecarboxylic acid as a metabolite of thiamine in rat urine. J Nutr $\mathbf{8 3}, 351-357$.

41. Suzuoki Z, Tominaga F, Matsuo T, et al. (1968) Metabolism of thiamine and thiamine tetrahydrofurfuryl disulfide to 4-methylthiazole-5-acetic acid in conventional and germfree rats under various dosing conditions. J Nutr 96, 433-444.

42. Amos WH \& Neal RA (1970) Isolation and identification of 3-(2'-methyl-4'-amino-5'-pyrimidylmethyl)-4-methylthiazole5-acetic acid (thiamine acetic acid) and 2-methyl-4-amino5 -formylaminomethylpyrimidine as metabolites of thiamine in the rat. J Biol Chem 245, 5643-5648.

43. Shibata K \& Onodera M (1992) Changes in the conversion rate of tryptophan-nicotinamide according to dietary fat and protein levels. Biosci Biotechnol Biochem 56, $1104-1108$

44. Frank O, Baker H \& Leevy CM (1964) Vitamin-binding capacity of experimentally injured liver. Nature 203, 302-303.

45. Collins TD, Eisenga BH, Bhandari SD, et al. (1992) Effects of ethanol on tissue folate incorporation and recovery from folate deficiency in rats. Alcohol Clin Exp Res 16, 757-763.

46. Tamura H \& Halsted CH (1983) Folate turnover in chronically alcoholic monkeys. J Lab Clin Med 101, 623-628. 
47. McMartin KE (1984) Increased urinary folate excretion and decreased plasma folate levels in the rat after acute ethanol treatment. Alcohol Clin Exp Res 8, 172-178.

48. Eichner ER \& Hillman RS (1973) Effect of alcohol on serum folate level. J Clin Invest 52, 584-591.

49. Paine CJ, Eichner ER \& Dickson V (1973) Concordance of radioassay and microbiological assay in the study of the ethanol-induced fall in serum folate level. Am J Med Sci 266, 134-138.

50. McMartin KE \& Collins TD (1983) Role of ethanol metabolism in the alcohol-induced increase in urinary folate excretion in rats. Biochem Pharmacol 32, 2549-2555.
51. McMartin KE, Collins TD \& Bairnfather L (1986) Cumulative excess urinary excretion of folate in rats after repeated ethanol treatment. J Nutr 116, 1316-1325.

52. McMartin KE, Collins TD, Eisenga BH, et al. (1989) Effects of chronic ethanol and diet treatment on urinary folate excretion and development of folate deficiency in the rat. J Nutr 119, 1490-1497.

53. Romanoff RL, Ross DM \& McMartin KE (2007) Acute ethanol exposure inhibits renal folate transport, but repeated exposure upregulates folate transport proteins in rats and human cells. J Nutr 137, 1260-1265. 